\title{
Stay or Leave: What Factors Are Necessary to Persist in Mathematics Doctoral Programs in the U.S.? Perspectives from International Students
}

Dung Tran

\begin{abstract}
Introduction
The mathematical community has recently become concerned about enrolling and keeping more students in doctoral programs. In particular, the attrition rate of students in Ph.D. programs in mathematics is alarmingly high and continues to increase. A. H. Herzig stated, "Despite the growing of scientific and quantitative needs of the twentyfirst century, relatively small numbers of U.S. students develop and maintain an interest in studying science and mathematics" [6, p. 171]. In institutions of higher education in the United States, doctoral candidates in mathematics typically include American and international students with diverse backgrounds. The graduate students who had completed their college education at U.S. institutions often felt they were at a disadvantage compared to international students whose undergraduate training in mathematics was more advanced [5]. Given the increasing number of international students enrolled in doctoral programs, a companion question is, "What do international students in a Ph.D. program in mathematics experience?"

Foreign-born scientists and engineers are important for the security of the United States. This feeling was voiced by the president of the National Academy of Engineering: "Foreign-born scientists and engineers have come to the United States, stayed in large numbers, and we are more prosperous and more secure, in large part, because of them!" [9, p. 1]. In fact, in 2008 approximately 46.7 percent of students earning a Ph.D. in mathematics were international [7]. Exploring international students' perspectives about success in mathematics
\end{abstract}

Dung Tran was a lecturer in the mathematics department at Hue University College of Education, Vietnam, and is currently a Ph.D. candidate in mathematics education at the University of Missouri Columbia. His email address is dtran@mai 1 . missouri .edu.

DOI: http://dx.doi.org/10.1090/noti1006 can facilitate the recruitment of international students for mathematics programs, as well as provide faculty members and administrators information that will be useful in establishing programs that provide a positive and supporting environment for international students.

This case study was done to gain a better understanding of the perspectives of international students pursuing a Ph.D. in mathematics and to learn why international students endure, persist, and successfully complete intensive doctoral programs. Furthermore, examining the academic life of doctoral students in mathematics may provide insight into the characteristics needed to succeed in the program.

\section{Methods}

The case study involved two Ph.D. students at a Midwestern university. Data collected included interviews, field notes, and related documents such as statements of purpose in their portfolios and writings regarding their beliefs about mathematics. As a native of Vietnam, I have also served as a lecturer in a mathematics department at a university in that country. Hence my beliefs about mathematics and mathematics careers were similar to those of the participants. Furthermore, being a part of the Vietnamese culture and studying at the same university with them for three years helped shape more valid interpretations. This study in no way seeks to be a generalization for all international students but instead aims to provide in-depth perspectives of Vietnamese students through this typical case.

In mathematics, we use an arbitrary case to draw an inference for all. However, such inferences cannot be made for social phenomena. Instead, people can start with typical cases or extreme outlier cases to gain in-depth information related to a phenomenon. While students from each country have their own unique cultural roots, looking specifically at Vietnamese students' experiences in the doctoral program may provide a new and useful perspective that will provide 
more knowledge about international students engaged in the programs.

The two participating students come from Vietnam; both are male, twenty-eight years of age, and from working class families. For the remainder of this paper the two students will be referred to as Dan and Victor. They are currently full-time Ph.D. students in the mathematics department of a research-intensive Midwestern university. During the 2011-2012 school year, this school's mathematics department consisted of thirty-six tenure-track faculty members, twenty nontenuretrack faculty members, nine postdoctoral fellows, and seventy-seven master's and Ph.D. students. Over the last five years, thirty-six Ph.D. students have graduated (see Table 1).

\begin{tabular}{|l|c|}
\hline School Year & $\begin{array}{c}\text { Number of Ph.D. students } \\
\text { graduating }\end{array}$ \\
\hline $2007-2008$ & 9 \\
\hline $2008-2009$ & 8 \\
\hline $2009-2010$ & 8 \\
\hline $2010-2011$ & 9 \\
\hline Fall-2011 & 2 \\
\hline
\end{tabular}

Table 1. Number of Ph.D. students graduating in five recent years.

Qualifying exams, including analysis and algebra tests, occur twice during the school year, once in January and once in July. Ph.D. students can take the exam more than once if they do not pass the exam the first time.

Both students participated in multiple Vietnamese competitions for talented students in mathematics in secondary school. They were also in the Honors Program in Vietnam, a program that recognizes talented high school students in specific subject areas. Students in the program devoted approximately fifteen hours per week to studying mathematics and to preparing for Vietnamese national competitions for talented students. They spent only one year finishing a three-year curriculum for high school students and used the remaining time to study advanced mathematics through special mentoring.

Dan and Victor finished their undergraduate program in mathematics and mathematics education, respectively, in Vietnam. After finishing their undergraduate degrees, they were selected to be lecturers for the mathematics departments where they studied, a common occurrence in most universities in Vietnam for students who excel in their studies. Dan was awarded his master's degree in mathematics from an institution in France. He took coursework in Vietnam with primarily French professors and then completed his thesis, written in English, in France. Victor completed one year of his master's degree at the university where he taught and then transferred to the Institution of
Mathematics, the best academic program in mathematics in Vietnam, for another year. He decided to come to the United States after being admitted into the program without finishing his master's degree.

Dan and Victor both had the goal of going abroad, in particular to the United States, to complete their Ph.D. degrees in mathematics because of the reputation that the United States has for a "very good educational system," "good academia," or "top professors in the field." In addition, it is difficult to study mathematics in Vietnam because there is a lack of funding for research and there is not a strong community of mathematicians to help students accomplish their goals. At the time of this study Dan was in his third year of the Ph.D. program and Victor was in his fourth year of the program. They both received university fellowships for their first year in the program and assistantships from the university for the following years.

\section{Stay or Leave: What Are the Factors?}

\section{Love for Mathematics}

Dan and Victor shared the same belief that one needs to have talent to succeed in a Ph.D. program in mathematics. Learning mathematics was the way Victor used to show his "competitive intellect"; he participated in the Competition for Talented Students in Mathematics when he was a student in secondary school. Dan felt he possessed the talent to be successful in mathematics as well: "It seemed like I have a little talent in math." This belief tended to remain as they learned more about mathematics. "When I read more about math and learned math, I see that to succeed in mathematics, you need some kind of talents, specially the way you think," said Victor. They both mentioned that "potentials" in the field and "confidence" are prerequisites to studying mathematics. Furthermore, they both believed that the talent one has in mathematics was inherent and that this talent cannot be initiated within their programs. Although they admitted hard work is really necessary for success in mathematics programs, it is not "sufficient". Dan stated:

\begin{abstract}
After all, learning math is innate; I mean it is not trained, through your process of learning, the talent will be discovered. I am not sure if we can train someone to study math, or help a kid orient to study math in the future.
\end{abstract}

Their love of mathematics is an important part of their lives. In one of Victor's essay writings about mathematics, he compared mathematics to a beautiful charming girl he fell in love with. He started to regard mathematics as his immortal love in which he could find "absolute silence in his soul, the moment of aspiration, and the highly delighted moment." Dan and Victor had the same attitude towards mathematics, but the ways in 
which they became interested in mathematics were different. Victor's interest came from his reading about mathematicians who were very peculiar in how they devoted their entire lives to the study of mathematics even if they were in danger or had to make many sacrifices to continue studying math. With Dan, he came to be inspired towards mathematics with the Competition for Talented Students in Mathematics where he could prove that his success was innate for mathematics. In addition, Dan became interested in mathematics when he solved a multitude of problems in the Journal of Mathematics and Youth, a very famous journal for elementary mathematics in Vietnam containing highly challenging problems, and later inspired by his professors when he studied mathematics in his program.

They also regarded mathematics as their career, their "most important" life path. They chose to become professors in mathematics where they could teach and do mathematics as authentic mathematicians, and this was also the reason they chose to enter their Ph.D. programs. As Victor said:

Well, it turns out that being a mathematician is so far away from being rich and famous. If one considers success as being rich and famous, one might not choose to be a mathematician. For me, I just love math so much so that I would be happy if I could do math and earn a living by doing math. I don't have a desire to be rich or famous.

Similarly, Dan wrote in his Statement of Purpose when applying for his Ph.D. program, "I can fulfill my lifelong dream of becoming a mathematician." Also his experiences in research made him "strongly believe that I will perform well in your [the] Ph.D. program and become a competitive mathematician."

\section{Early Readiness for Milestones}

Both students specified their subfields, analysis for Dan and algebraic geometry for Victor, during their programs at their undergraduate and master's institutions in Vietnam, allowing them to easily determine what courses to take during their first semester in the doctoral program. They also took two courses to prepare for the qualifying exams at the end of the first semester, including basic algebra and basic analysis. These two courses are designed for Ph.D. students, but both of them regard the courses as preparation "for master's students to pass the qualifying exam as well as for Ph.D. students to review basic knowledge in mathematics."

Dan's and Victor's scores were the highest among all students taking the qualifying exams; Dan received the highest score in the analysis test and Victor in the algebra test, coinciding with their subfields. The time they devoted to preparing for the exams ranged from one to three weeks after finishing the first semester in the Ph.D. program. However, they agreed that to succeed one should "accumulate knowledge on the way of learning," as it is not possible to wait until the exam and then prepare for several weeks. They used the short time during winter break to review and to practice "mathematics solving skills" and "techniques" for the problems related to the exams.

Highly determined, they continued to choose their coursework related to their research interests, which became "deeper and more specialized", and some courses of their "particular concern". The courses prepared as background and helped Dan and Victor know more about mathematics so that they could "communicate with others in conferences or outside of their subfield." Their perceptions about coursework changed during the program. For Victor, “The more I take classes, the worse I feel. Gradually, I tend to read books by myself." He described his ideal mathematics teaching style in a Ph.D. program as one in which the professor should be the person who guides the discussion and the students must "discover the idea" after they prepare and read the materials before class sessions. Dan, in contrast, expressed that, "Yes, I learn a lot of interesting knowledge from the classes," and he said they really helped him to "build up background" and prepared him for "doing research in the future."

Along with taking courses after the qualifying exam, they began focusing more on their research goals after the first semester, which they were familiar with from their undergraduate and master's programs. They started early working with their professors on the problems of interest. In the fourth year, Victor earned an award from the department for being the best student in research.

\section{Close Relationship with Advisor}

When choosing to apply to the university, they sought to find advisors who were among the best professors in their research fields of interest. With respect for his advisor, Victor valued his advisor's opinion and said, "Yes, before choosing courses, I always ask him first. His advice has significant impact on my choices. I think about 60 percent of my decisions have been influenced from him" even though Victor already knew what courses he should choose as part of his program to prepare for the qualifying exam, to support his research focus, or to learn more about his interests. Dan had a similar high regard for his advisor's opinion.

The role of advisor seems to be determinant in specifying a research focus. "For me, I specified my research trends when I chose my advisor. I mean, I knew I would do research related to his interest. Advisors often offer problems for their students to do," said Dan. At a very early stage in the program, 
they started research in their fields of interest. This academic activity helped the students have the feeling of doing mathematics as well as focusing on the problems they will complete for their dissertations.

The relationship with their advisors developed throughout the program, especially when they proved themselves. They both showed respect when talking about their advisors whether the relationship was in or outside of class. Victor said, "He's not only a good teacher in class but he's also very understanding and considerate outside the classroom." He described some "accidents" that helped him bond closer to his advisor:

Well, we had a long journey before we could really understand each other well and know how the other thinks. For example, we were really extremely serious in a discussion in which we had different ideas of proving a lemma. That would have been worse but in the end we just realized that we were too serious and we both laughed.

The close relationship Victor had with his advisor made him confident to talk about his advisor's beliefs about mathematics and strengthened his passion for math.

Very early in his program, Dan carefully said about this relationship, "Good, most of the professors here are very nice. Whenever I have difficulty, they are eager to help." He said, "But if I am lazy, I don't want to meet with my advisor. For instance, when I have no result to report to him, I don't want to meet him." His advisor's working style somehow affects Dan's behavior; "They are very passionate to solve the problem thoroughly. When the problem results are not finished, they often suggest students to continue to solve." Establishing a good rapport with his advisor later in the program, Dan felt more comfortable sharing his ideas and sought help from his advisor.

\section{Cultural Advantages}

Dan and Victor began to be interested in mathematics when they were young and participated in competitions for those gifted in mathematics. They devoted a great deal of time, even double or triple the time other students devoted, to solving mathematical problems and to working on deeper and more general topics in the program, as well as to preparing for the exams. At an early age, they "liked mathematics and they liked the competitions" because they believed "the competitions also measured one's ability.”

Both chose mathematics for their undergraduate program in Vietnam where they took courses focused on advanced mathematics, which provided them an appreciation for learning mathematics. They felt familiar with the content in their classes in the Ph.D. program because they had a chance to learn some of it at their undergraduate and master's institutions. In particular, when talking about the courses he took to prepare for the qualifying exam, Victor said, “Actually, two courses that I took... some like... the knowledge I have already built up for me in Vietnam." Consistent with what Victor said, Dan asserted, "Yes, my background in Vietnam was really helpful. I just had to review to prepare for the exam." This first orientation in mathematics helped the students specify their goal of mathematics very early. More importantly, they completed a thesis when they graduated from their undergraduate institutions based on original research in mathematics related to the problem their advisors were concerned with in their subfield.

Even though they admitted that sometimes they had difficulties speaking English at the very start of their program, it was not really a barrier for them to study mathematics. Sometimes they mentioned it was "difficult to get involved" or "to make friends" with students from different fields of study, but it didn't really matter. Both admitted that Vietnamese had advantages when learning mathematics, which helped them to get involved with the community very early. Victor thought, "Asians are smart, that is one of the advantages." Dan said,

When I study in Vietnam, I have effort. This motivation is really helpful when I study here. When I have difficulty, I try to solve. I am not sure that is the case for U.S. students; maybe they do not try as hard as Vietnamese.

They thought that Vietnam and Asian countries focus on "test-oriented studying and are very competitive, so students try their best when working” to be successful-sink or swim. They shared the same thought that many students in Vietnam would like to study the formal sciences, which may not be practical at the time; in particular, they dealt a lot with pure mathematics with abstract levels early in their undergraduate programs. One thing to notice is that every student in Vietnam takes calculus in high school, so in their Honors Program, they studied much more advanced mathematics.

Their rich background in mathematics, their comfort with the program, their success in the program, and their desire to have a career as a mathematician caused both students to never consider leaving their Ph.D. program.

\section{Discussion}

The community of mathematicians sets expectations and students who are able or willing to adapt themselves to these U.S. cultural practices tend to be successful [6]. Mathematics is believed to be a discipline that is objective and emotion-free [1]; however these two Vietnamese students showed 
a different opinion. More specifically, both Victor and Dan were enthusiastic about mathematics and loved mathematics, and they felt mathematics could be subjective from the lens through which people look.

Students who enter graduate school participate in two distinct sequential communities of practice. In the first three years of study, students primarily participate in courses leading up to qualifying exams. Once they complete these requirements, they can begin looking for a research area/emphasis and learn to do research. V. Tinto stated that the first stage is far different from the activities of practicing mathematicians [8]. Proving themselves and examining their ability to be ready for the second stage in the program, both students built up more meaningful integration and relationships with advisors and other members in the community.

Mathematics is generally regarded as an objective field of knowledge in which mathematicians work to discover truths about the nature of the world [4]. This presumed objectivity of mathematics leads to a cultural blindness to personal issues in which students who do not correspond to the cultural norm (male, white, childless, self-assured) are at a disadvantage [3]. However, success in mathematics can be achieved by all; regardless of race or ethnicity. Dan and Victor asserted that they had an advantage when studying mathematics. Their culture encouraged patience and perseverance in solving math problems, which makes them confident both in coursework and independent research in mathematics.

Mathematics is not fragmented, and most mathematicians are not obsessive about their own little corner in isolation or worried about how their work connects to mathematics in the same area or outside their area in the "real" world. Mathematics is really a "big picture" field of study, and the Vietnamese students are on their way to exploring the picture with persistence, readiness, and a willingness to consider mathematics as a lifetime career.

Students participate in research and related activities and then overcome obstacles in order to integrate into the research community to practice as a full participant. Features of the individuals, relationships developed at the institution, and programs are correlated with doctoral student persistence; the quality of experience in graduate school is a function of how well integrated the student is in the academic communities of his own department. The results of this study also provide suggestions for students pursuing a Ph.D. degree in mathematics and for the community of mathematicians to successfully recruit native and international students.

How students prepare for a Ph.D. program in mathematics. Carefully considering an individual's interest in mathematics is one of the crucial points for determining if a student is appropriate for the program. One's interest may vary from time to time at the secondary school level and during undergraduate study, but a commitment to working hard when confronted with unfamiliar mathematics, exhibiting exceptional persistence, having confidence, and expecting to complete complex mathematics tasks are important for long-term success in mathematics [2]. Moreover, the willingness to adapt to the "competitive" academia at the first stage of the program sets the stage for selfproving and for building up meaningful integration into the environment later.

The qualifying exam often happens during the first years of the program, and students should be prepared for it. There is a big gap between undergraduate programs in mathematics and Ph.D. programs. The first year in the Ph.D. program may be overwhelming if students do not have a good background in mathematics. This is not the time to take courses to supplement basic knowledge for the exam or to transfer into the program [5]. Students should be prepared for the exam by equipping themselves with the knowledge before enrolling in the program. Students may consider taking a master's program before applying for a Ph.D. when the undergraduate program does not incorporate advanced mathematics. This transition step helps examine the student's interest in mathematics again and prepares students for their research experience.

Building up a good relationship with advisors and faculty members is essential for persistence in the program, but students need to be ready to prove themselves first. Students' interaction with faculty members during the first year of the program mostly occurs while listening to lectures in classes [5], [6], [8]. One should accept the role as a graduate student because treatment as "junior colleagues" is rare. Be focused, and be ready to feel isolated as you face the early challenges of the program.

What role do faculty members play supporting doctoral students? Some students select mathematics because of a genuine interest in mathematics. However, many people find that the reality of being enrolled in mathematics does not meet their expectations [6]. Transferring the beauty of mathematics to students through courses, office hours, or whenever interacting with them is helpful for them to keep their initial interest. Mathematics is a "big picture" field, but most students see one tiny piece of the picture, so that they do not see its beauty. Students need early moral support and encouragement to persist in the program.

The obstacles that students often encounter come from program structure or even from faculty members' beliefs about mathematics teaching and learning [5], [6]. Looking at students' mathematics backgrounds can serve as a predictor for their 
NEW

\section{AMS JOURNALS FEATURES!}

\section{Enbanced References}

[7] Michael Freedman, Joel Hass, and Peter Scott, Least area incompressible surfaces in 3-manifolds, Invent. Math. 71 (1983), no. 3, 609-642. MR 695910 (85e:57012), http://dx.doi. org /10,007 BF02095997

[8] A. M. Gleason, Thr structure of locally compact groups, Duke Math. J.18 (1951), 85-104. MR $0039730(12,589 \mathrm{a})$

[9] Andrew M. Gleason, Groups hivithout small subgroups, Ann. of Math. (2) 56 (1952), 193-212. MR $0049203(14,135 \mathrm{C})$

[10] W. H. Gottschalk, Minimal sets: an intrond ction to topoiosical dvnamics. Bull. Amer. Math. Soc. 64 (1958), 366-351. MR 0100048 (20 \#644), http ///dx

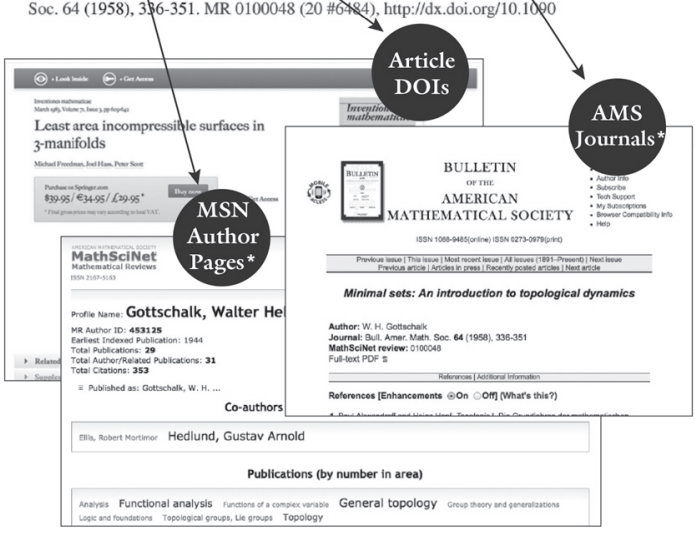

The all-new enhanced AMS journal references now present greater opportunities for users to access valuable information in the mathematical sciences literature. Enhanced references, which are offered for select journals, combine authors' bibliographies with data from MathSciNet $^{\circledR}$ to provide additional features, as listed below. The references also deliver more complete and standardized bibliographic information.

Enhanced references provide direct links to:

- Articles via DOI (Digital Object Identifier)

- MathSciNet author pages*

- Journal articles published by the AMS*

For more information, visit:

www.ams.org/publications/ journals/references

* Requires a subscription

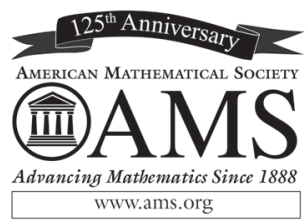

persistence in the program. Each student has his own learning trajectory, and receiving timely support from faculty members can help them succeed in the program. Recruiting international students who are ready to pursue a career in mathematics is of importance. Culture shock and language barriers are not big problems for students in mathematics. As Galileo stated, "The Universe is written in the language of mathematics" [4, p. 135].

Graduate students can be actively cultivated and provided with a nurturing environment that allows the largest possible number of them to be successful. Or they can be put in a demanding environment with little support so that whoever is not willing to adapt will not survive. The way Ph.D. students are educated in their programs may likely provide a model that they will emulate in their future careers so a self-perpetuating "domino effect" is created. The success of a student all depends on faculty members' beliefs about teaching and learning mathematics in the Ph.D. program.

\section{References}

[1] L. BURTON, The practices of mathematicians: What do they tell us about coming to know mathematics?, Educational Studies in Mathematics 37 (1998), 121-143.

[2] M. P. CARLSON, The mathematical behavior of six successful mathematics graduate students: Influences leading to mathematical success, Educational Studies in Mathematics 40 (1999), 237-258.

[3] H. EtzKowitz, C. Kemelgor, M. Neuschatz, and B. UzzI, Athena unbound: Barriers to women in academic science and engineering, Science and Public Policy 19 (1992), 157-179.

[4] J. GLIMM, Mathematical perspectives: Reflections and prospectives, Bulletin of the American Mathematical Society 47 (2009), 127-136.

[5] A. H. HeRzIG, Where have all the students gone? Participation of doctoral students in authentic mathematical activity as a necessary condition for persistence toward the Ph.D., Educational Studies in Mathematics 50 (2002), 177-212.

[6] ____ Becoming mathematicians: Women and students of color choosing and leaving doctoral mathematics, Review of Educational Research 74 (2004), 171-214.

[7] National Science Foundation, Doctorate recipients from U.S. Universities: Summary Report 2007-08, 2009. Retrieved on June 23, 2010, from http: //www . nsf.gov/statistics/nsf10309/

[8] V. TINTO, Leaving College: Rethinking the Causes and Cures of Student Attrition (2nd ed.), University of Chicago Press, Chicago, 1993.

[9] W. A. WULF, The importance of foreign-born scientists and engineers to the security of the United States, 2005. From http://www7. nationalacademies. org/ocga/testimony/Visas_for_Foreign_ Scholars_and_Students.asp. 